\title{
A close correlation in the expression patterns of Af- 6 and Usp9x in Sertoli and granulosa cells of mouse testis and ovary
}

\author{
Takeshi Sato, Yoshiakira Kanai, Takashi Noma, Masami Kanai-Azuma ${ }^{2}$, Shinichiro Taya ${ }^{3}$, \\ Toshiyasu Matsui, Maki Ishii, Hayato Kawakami², Masamichi Kurohmaru, Kozo Kaibuchi ${ }^{3}$, \\ Stephen A Wood ${ }^{4}$ and Yoshihiro Hayashi ${ }^{1}$
}

Department of Veterinary Anatomy and ${ }^{1}$ Department of Global Agricultural Sciences, The University of Tokyo, Yayoi 1-1-1, Bunkyo-ku, Tokyo 113-8657, Japan, ${ }^{3}$ Department of Anatomy, Kyorin University School of Medicine, Mitaka, Tokyo, 181-8611, Japan, ${ }^{2}$ Department of Cell Pharmacology, Nagoya University, Graduate School of Medicine, 65 Tsurumai, Showa, Nagoya 466-8550, Japan, ${ }^{3}$ The Child Health Research Institute, 72 King William Rd, North Adelaide, South Australia 5006, Australia

Correspondence should be addressed to Y Kanai; Email: aykanai@mail.ecc.u-tokyo.ac.jp

\begin{abstract}
Usp9x, an X-linked deubiquitylating enzyme, is stage dependently expressed in the supporting cells (i.e. Sertoli cells and granulosa cells) and germ cells during mouse gametogenesis. Af-6, a cell junction protein, has been identified as a substrate of Usp9x, suggesting a possible association between Usp9x and Af-6 in spermatogenesis and oogenesis. In this study, we examined the expression pattern of Af-6 and Usp9x and their intracellular localization in testes and ovaries of mice treated with or without pregnant mare serum gonadotropin (PMSG), an FSH-like hormone. In both testes and ovaries, Af-6 expression was predominantly observed in supporting cells, as well as in steroidogenic cells, but not in any germ cells. In Sertoli cells, Af-6 was continuously expressed throughout postnatal and adult stages, where both Af- 6 and Usp9x were enriched at the sites of Sertoli-Sertoli and Sertoli-spermatid junctions especially at stages XI-VI. In the granulosa cells, Af-6, as well as Usp9x, was highly expressed in primordial and primary follicles, but its expression rapidly decreased after the late-secondary follicle stage. Interestingly, in PMSG-treated mice, the expression levels of Af-6 and Usp9x were synchronously enhanced, slightly in Sertoli cells and strongly in granulosa cells of the late-secondary and Graafian follicles. Such closely correlated expression patterns between Af-6 and Usp9x clearly suggest that Af-6 may be deubiquitylated by Usp9x in both Sertoli and granulosa cells. It further suggests that the post-translational regulation of Af- 6 by Usp9x may be one potential pathway to control the cell adhesion dynamics in mammalian gametogenesis.

Reproduction (2004) 128 583-594
\end{abstract}

\section{Introduction}

Protein ubiquitylation is a dynamic and reversible process regulated by ubiquitin ligases and deubiquitylating proteases. This regulation of protein stability by the ubiquitinproteasome pathway plays a role in a vast range of biological processes (Hershko \& Ciechanover 1998). Drosophila fat facet ( faf) gene, which encodes an ubiquitin-specific protease, has been shown to be important in oocyte development and eye formation (Fischer-Vize et al. 1992, Huang et al. 1995, Cadavid et al. 2000, Chen \& Fischer 2002, Chen et al. 2002). In mice and humans, two faf homologous genes with a high sequence similarity have been isolated on sex chromosomes: X-linked Usp9x (also known as Fam or Dffrx) (Jones et al. 1996, Wood et al. 1997, Brown et al. 1998) and Y-linked Usp9y (also known as Dffry) (Jones et al. 1996, Hall et al. 2003). Mouse Usp9y is a testis-specific gene, which is probably expressed in spermatogenic cell lineage (Jones et al. 1996). A de novo point mutation in human USPYY has been identified in an azoospermic man (Sun et al. 1999), suggesting its essential role in spermatogenesis. Human USP9X was originally isolated as a possible candidate gene for the defects of oocyte proliferation and subsequent gonadal degeneration found in Turner syndrome (Jones et al. 1996). In mice, Usp9x expression shows a stage-specific pattern in supporting cells (i.e. Sertoli cells in testis and granulosa cells in ovary) and germ cells during gonadal development and gametogenesis (Noma et al. 2002). Since Usp9x is able to substitute for faf in all essential functions in Drosophila (Chen et al. 2000), these reports clearly suggest that Usp9x may have an important function as a substrate-specific regulator of the proteasome-dependent degradation in mammalian gametogenesis. 
On the other hand, Af-6 (also known as Afadin) is an integral component of tight and adherens junctions (Yamamoto et al. 1997, Mandai et al. 1997), which is essential for epithelial cell-cell contact and cell polarity (Ikeda et al. 1999, Zhadanov et al. 1999). In polarized epithelial cells, Af-6 is localized at the actin-based cellcell adhesion sites such as tight and adherens junctions (Mandai et al. 1997, Yamamoto et al. 1997), where it associates with a tight junction protein ZO-1 (Yamamoto et al. 1997), immunoglobulin-like cell adhesion molecules, nectin (Miyahara et al. 2000, Takai \& Nakanishi 2003) and junctional adhesion molecule (Ebnet et al. 2000). Af- 6 has also been shown to bind to a number of signaling molecules such as Ras family GTPases including Rap1 and Ras (Kuriyama et al. 1996, Linnemann et al. 1999, Boettner et al. 2000) and subsets of Eph-related receptor protein tyrosine kinases (Hock et al. 1998, Buchert et al. 1999). Moreover, several biochemical analyses suggest that Af- 6 may also possess a signal-mediating function, regulating the dynamic junction regeneration and cell adhesion in response to specific extracellular signals (Su et al. 2003, Radziwill et al. 2003).

During mammalian gametogenesis, the dynamic formation and degeneration of the junctional alignment in both Sertoli and granulosa cells are important in spermiation and spermatogenic cell movement across the seminiferous epithelium (spermatogenesis) (Cheng \& Mruk 2002) and in ovulation and follicle development (oogenesis) (Fair 2003). Most interestingly, Af-6 has been shown to be one substrate of Usp9x in MDCK cells (Taya et al. 1998), although no appreciable genetic interaction was found between Usp9x ( faf) and Af-6 (canoe) homologues in Drosophila eye development (Chen et al. 2000). In MDCK cells, Af-6 interacts with Usp9x both in vivo and in vitro, Af- 6 is ubiquitylated in intact cells and Usp9x prevents the ubiquitylation of Af- 6 in this cell line. In mouse twocell embryos, the depletion of Usp9x protein also induces the rapid decline of total Af- 6 expression level and its mislocalization at the apical surface of blastomeres, which results in an inhibition of cell adhesive events (Pantaleon et al. 2001). Therefore, with regard to a stage-specific Usp9x expression pattern in Sertoli and granulosa cells (Noma et al. 2002, this study), these findings suggest the possibility that the post-translational regulation of Af- 6 by Usp9x may be one potential regulatory system of cell adhesion dynamics in both spermatogenesis and oogenesis. However, at present there is little information on the stage-specific changes in Af-6 localization and its association with Usp9x expression in gametogenesis, except for the report showing an enrichment of Af-6 in Sertoli-Sertoli and Sertoli-spermatid junctions of adult testis (Ozaki-Kuroda et al. 2002).

To clarify a possible association between Af- 6 and Usp9x in mammalian gametogenesis, in this study we examined the expression patterns of Af-6 and Usp9x in the testis and ovary by immunohistochemistry. Moreover, we analyzed the changes in their expression patterns in mice treated with or without pregnant mare serum gonadotropin (PMSG), a follicle-stimulating hormone (FSH)-like hormone, which was shown by in vitro experiments to affect the cell adhesiveness of Sertoli cells in the testis (Janecki et al. 1991) and granulosa cells in the ovary (Ben-Ze'ev 1987, Ben-Ze'ev \& Amsterdam 1987). As a result, the present study is the first to demonstrate a close correlation between Af-6 and Usp9x expression patterns in both Sertoli and granulosa cells during mouse gametogenesis.

\section{Materials and Methods}

\section{Animals}

ICR mice (five males and five females each at birth, 1, 2 and 4 weeks, five males and twelve females at 3 weeks, and thirteen males and seven females at 8 weeks; Japan SLC, Shizuda, Japan) were used in this study. As for the mice treated with PMSG, female mice (3 weeks) were injected i.p. with 7.5 units PMSG (Teikokuzouki, Tokyo, Japan) diluted in $0.2 \mathrm{ml} 10 \mathrm{mM}$ phosphate-buffered saline (PBS), following the PMSG treatment protocol to synchronize the ovarian cycles in the mice (Mitsunari et al. 1999, Zuccotti et al. 2002). For the PMSG-treated male mice, we also applied the same PMSG treatment protocol (i.e. i.p. injection of 7.5 units PMSG/mouse) to the adult male mice at 8 weeks to allow histological identification of the stage of the seminiferous epithelial cycle. In addition, treatment of adult male rats with 50 units PMSG (dose equivalent to 7.5 units/PMSG per mouse (body weight of adult males approximately $30 \mathrm{~g}$ in mice and $200 \mathrm{~g}$ in rats)) was reported to increase the testicular blood flow at $24 \mathrm{~h}$ post-injection (Bergh et al. 1992). Since our preliminary time-course experiment $(6,12,24$ and $48 \mathrm{~h}$ after PMSG injection; two male and female mice used at each sampling time-point) detected the highest immunoreactivity of anti-Af- 6 antibody (Ab) in both Sertoli and granulosa cells at $48 \mathrm{~h}$ post-injection, we mainly used the testes and ovaries of the mice at $48 \mathrm{~h}$ for the following immunohistochemical and immunoblot experiments. The animal experiments were conducted in accordance with the Guidelines for Animal Use and Experimentation as set out by the University of Tokyo.

\section{Immunohistochemistry}

The testes and ovaries were isolated at various stages (five mice each at postnatal stage and four adult 8-week mice of each sex), and fixed in Bouin's solution for $4 \mathrm{~h}$. They were dehydrated in ethanol, cleared in xylene, and then routinely embedded in paraffin. Paraffin sections were cut (5 $\mu \mathrm{m}$ in thickness) from at least four independent gonadal samples at each stage, and applied to immunohistochemistry using anti-Af-6 or Usp9x Ab as described previously (Kanai-Azuma et al. 2000, Noma et al. 2002). In brief, deparaffinized sections were first incubated with anti-Af-6 or anti-Usp9x Ab (each $2.5 \mu \mathrm{g} / \mathrm{ml}$ ) at $4{ }^{\circ} \mathrm{C}$ for $12 \mathrm{~h}$. After washing with Tris-buffered saline ( $\mathrm{pH}$ 7.5) several times, 
the reaction was visualized by horseradish peroxidase (HRP)-labeled goat anti-rabbit secondary $\mathrm{Ab}$ in combination with a Tyramide Signal Amplification kit (NEN Life Sciences Product, Wellesley, UK). For the comparative immunohistochemical analysis of the control and PMSGtreated gonads (three males at 8 weeks and three females at 3 weeks in each group), the procedures for fixation, embedding and immunohistochemical staining were performed as carefully as possible under the same conditions in order to evaluate the relative immunoreactivity. The same staining condition in each sample was also confirmed by the similar intensities of anti-Af- 6 staining in Leydig or theca cells between control and PMSG-treated samples (asterisks in Fig. 5a, b, e and f).

\section{Confocal immunofluorescence microscopy}

The testes and ovaries of adult mice ( 8 weeks; three mice of each sex) were fixed in $4 \%$ paraformaldehyde (PFA)PBS (pH 7.5) at $4{ }^{\circ} \mathrm{C}$ for $1 \mathrm{~h}$, and washed with cold PBS for $2-3 \mathrm{~h}$. After they were embedded in optimal cutting temperature (OCT) compound (Sakura Tissue-Tek, Tokyo, Japan), they were cooled in liquid nitrogen, and then frozen sections were cut at $8 \mu \mathrm{m}$ thickness from three independent gonadal samples. The sections were double stained with each primary $\mathrm{Ab}$ and AlexaFlour-conjugated phalloidin $(6.6 \mu \mathrm{M}$; Molecular Probes, Eugene, OR), and the Af-6 or Usp9x reaction was visualized with biotinylated anti-rabbit IgG Ab and streptavidin-Texas Red. After counterstaining with TO-PRO-3/DNA $(0.5 \mu \mathrm{M}$; Molecular Probes), they were finally observed with a LSM510 confocal laser scanning system (Carl Zeiss, Oberkochen, Germany). Moreover, non-specific reaction could not be detected in the germ cells and gonadal somatic cells when the sections were incubated with preimmune serum or normal IgG, instead of either anti-Af-6 or anti-Usp9x Ab.

\section{Immunoblot}

The testes ( 8 weeks; three males) and ovaries (3 weeks; four females) were isolated from the mice at $48 \mathrm{~h}$ postPMSG treatment as described above. Each tissue was washed twice with ice-cold PBS, homogenized in RIPA buffer $(50 \mathrm{mM}$ Tris- $\mathrm{HCl},(\mathrm{pH}$ 7.5), $150 \mathrm{mM} \mathrm{NaCl}, 0.5 \mathrm{mM}$ EDTA, $1 \%$ Triton $X$, and $1 \times$ protease inhibitor cocktail (Roche Diagnostics, Basel, Switzerland)), and centrifuged at $10000 \mathrm{~g}$ at $4^{\circ} \mathrm{C}$ for $30 \mathrm{~min}$. After the protein concentration of each supernatant was determined by the BCA Protein Assay Reagent Kit (Pierce Biotechnology, Rockford, IL, USA), $10 \mu \mathrm{g}$ of each sample was boiled with nonreduced SDS sample buffer, and electrophoresed in a 4$20 \%$ gradient gel. After the gels were transfered to nylon membranes, the blots were incubated with anti-Usp9x or anti-Af6 Ab (50 ng/ml each). The labeled protein was then visualized with HRP-labeled goat anti-rabbit $\lg \mathrm{Ab}$ in combination with the enhanced chemiluminescence detection kit (Amersham Pharmacia Biotech, Piscataway, NJ, USA) as described previously (Kanai et al. 1996).
In addition, approximately equal amounts of protein sample per lane were confirmed by Coomassie brilliant blue (CBB) staining of both the replica gels and the lower part of the identical gels (the gel pieces corresponding to the migration area with less than $30 \mathrm{kDa}$, which were separated before membrane transfer).

\section{Results}

\section{Localization of Af-6 and Usp9x in Sertoli cells}

Our previous studies have shown that Usp9x deubiquitylating enzyme is weakly expressed in Sertoli cells of the adult mouse testis (Noma et al. 2002) (Fig. 1e). To examine the localization of Af-6, a substrate of Usp9x, we first examined the expression of Af- 6 in the developing testes by conventional immunohistochemistry using paraffin sections. As a result, Af- 6 reactions were detected predominantly in Sertoli cells, Leydig cells and some interstitial stromal cells, but not in any germ cells, throughout the postnatal and adult stages (Fig. 1a-d). During postnatal periods, Af- 6 reactions were strongly observed in Sertoli cells from newborn to 4 weeks (Fig. 1a-c), although they were significantly reduced in Sertoli cells of 8-week testes (Fig. 1d). Moreover, the distribution pattern of both Af-6 and Usp9x reactions was found in a stage-dependent manner, diffuse in the Sertoli cell cytoplasm at stages $\mathrm{VII}-\mathrm{X}$ (lower right panels in Fig. $1 \mathrm{~d}$ and e), versus restricted to the basal area of the cytoplasm at stages $\mathrm{XI}-\mathrm{VI}$ (lower left panels in Fig. 1d and e). These findings therefore suggest that Af- 6 is co-localized with Usp9x in Sertoli cells, and both Af-6 and Usp9x show some stage-dependent synchronous changes in their intracellular distribution.

Next, to analyze their detailed intercellular localizations, we performed double staining of anti-Af- 6 or Usp9x Ab with AlexaFlour-conjugated phalloidin (staining F-actin) by using PFA-fixed frozen sections, and then analyzed them under a confocal laser scanning microscope (Fig. 2). Confocal analysis also revealed a stage-dependent alteration in their intracellular localization at the sites of the actin-mediated junctions of Sertoli cells. In short, at stages VII-X Af- 6 reactions were diffusely detected in the basal compartment around spermatogonia and in the area adjacent to spermatocytes and spermatids, which include the Sertoli-Sertoli and Sertoli-spermatid ectoplasmic specializations (yellow; small and large arrows in Fig. 2a respectively). Moreover, positive reactions with antiUsp9x Ab were more widely observed throughout the whole cytoplasm of Sertoli cells at these stages (Fig. 2c). In contrast to such a diffuse distribution pattern of both Af- 6 and Usp9x at stages VII-X, their reactions were more restricted to these two junctional sites of the ectoplasmic specialization in Sertoli cells at stages $\mathrm{XI}-\mathrm{VI}$ (yellow; small and large arrows in Fig. $2 b$ and d). These findings clearly suggest that Af-6 is co-localized with Usp9x at the sites of the inter-Sertoli junctional complex and Sertoli-spermatid adherens junction, especially at stages 

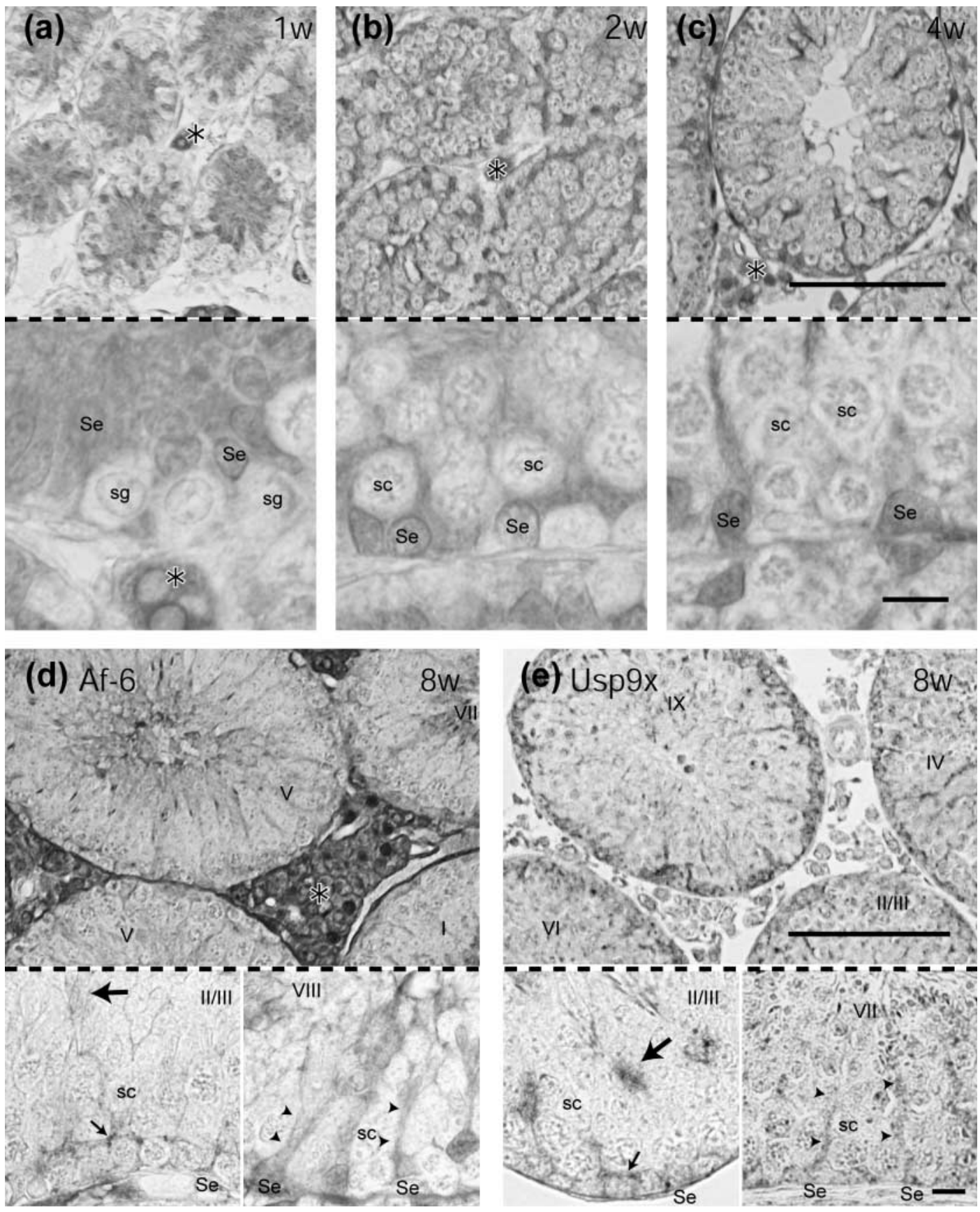

Figure 1 A close correlation of expression patterns between Af-6 (a-d) and Usp9x (e) in Sertoli cells of mouse testes. Af- 6 expression is predominantly observed in Sertoli (Se) and Leydig cells (asterisks) throughout postnatal development (1 week (a), 2 weeks (b) and 4 weeks (c)), but its expression is significantly reduced in Sertoli cells at the adult stage (8 weeks (d)). Usp9x is specifically expressed in Sertoli cells (e). In adult Sertoli cells, the reactions of both Af-6 and Usp9x are diffusely observed in the whole cytoplasm at stages VII-X (arrowheads; lower right-hand plates in $\mathrm{d}$ and e), in contrast to their restricted localization in the basal compartment and the spermatid-adjacent area of their cytoplasm at stages XI-VI (small and large arrows; lower left-hand plates in $\mathrm{d}$ and e). In each part, the lower plate shows a more highly magnified image of the similar section of the upper plate. Each Roman numeral labeled on seminiferous epithelium shows the cycle stage. Se, Sertoli cell; sg, spermatogonia; sc, spermatocyte. Scale bars in the lower plates of (c and e) represent $10 \mu \mathrm{m}$, while the other bars represent $100 \mu \mathrm{m}$. 

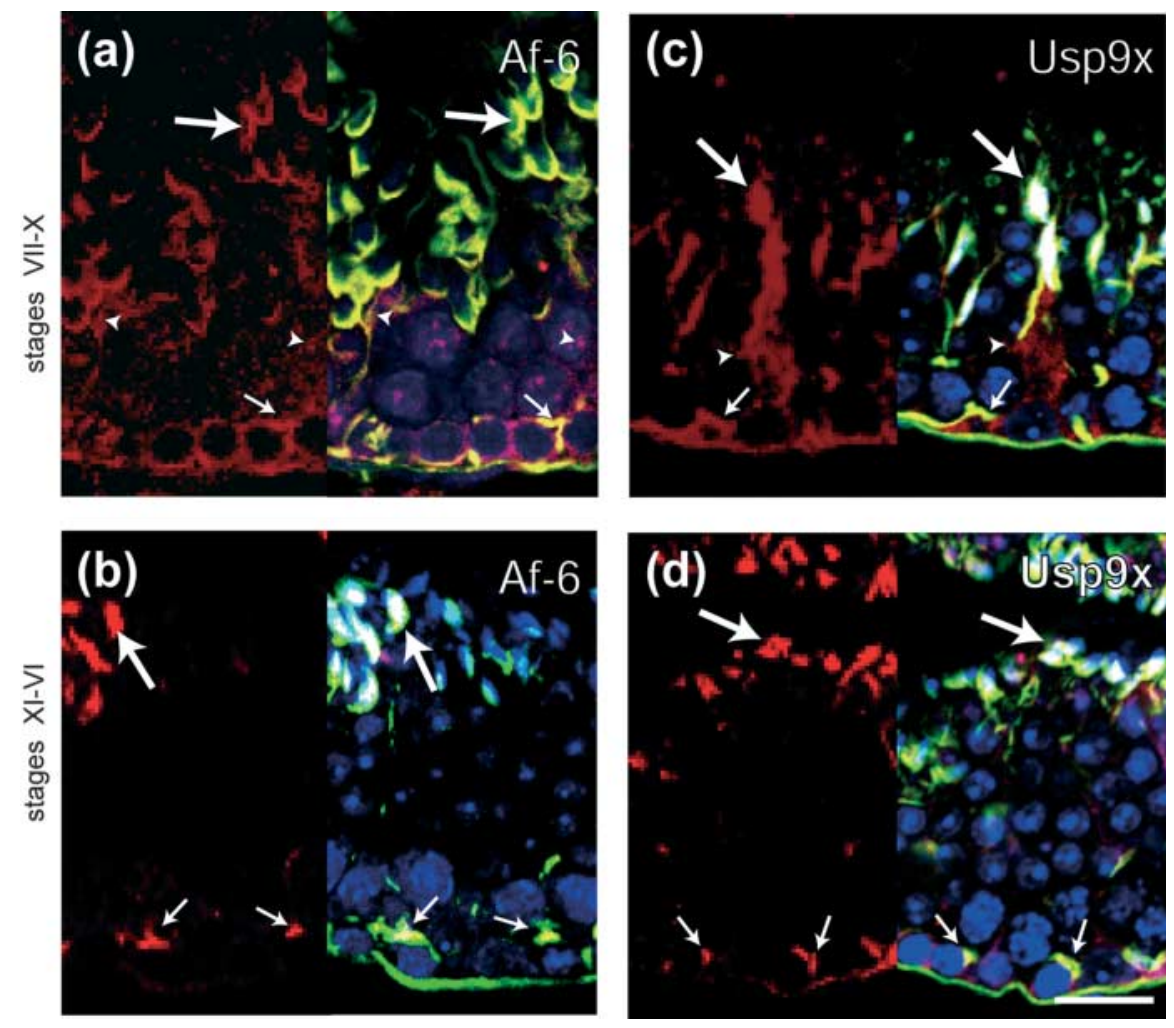

Figure 2 A stage-dependent synchronous alternation in intracellular localization of Af-6 (a and b) and Usp9x (c and d) in matured Sertoli cells. (a and c) At stages VII-X ((a) stage VIII; (c) stage IX), positive reactions of both Af-6 (red in (a)) and Usp9x (red in (c)) in Sertoli cells are diffusely distributed in their cytoplasm including Sertoli-Sertoli (small arrows) and Sertoli-spermatid (large arrows) ectoplasmic specializations, which are visualized as the yellow color in the right-hand panels of a and c. Arrowheads show the positive reaction in the area except for these two actin-based junctions. (b and d) At the XI-VI stages ((b) stage IV; (d) stage IV), their reactions are restricted to the two sites of these actin-based junctions (red and yellow reactions in the left- and right-hand plates of $b$ and $d$ respectively). In each part, the right-hand plate exhibits the combined image of Af-6 or Usp9x expression (red) with F-actin staining (green) and nuclear staining (blue) in the same section. Red staining, Af-6 or Usp9x; green staining, actin; yellow staining, co-localization of red and green staining; blue staining, nuclei. Scale bars represent $10 \mu \mathrm{m}$.

$\mathrm{XI}-\mathrm{VI}$, and that both Af-6 and Usp9x molecules may synchronously transit between the junctional sites and the cytoplasm in a stage-dependent manner.

\section{Stage-dependent expression of Af-6 shows a close correlation with Usp9x expression profile in ovarian granulosa cells}

In ovarian granulosa cells, Usp9x expression has been previously shown to be regulated in a stage-dependent manner: it is strongly expressed in primordial and primary follicles, weakly in secondary follicles and undetectable in Graafian follicles (Noma et al. 2002) (Fig. 3e). The present immunohistochemical analysis clearly showed that Af-6 expression resembles the Usp9x expression pattern during follicle development (Fig. 3a-d). In the 1-week ovary, Af- 6 expression was predominantly found in granulosa cells of primordial follicles (arrows in Fig. 3a). In granulosa cells of ovaries from 2-week to 8-week adults, such reactions were continuously observed in all primordial and primary follicles and weakly in some secondary follicles, but they completely disappeared in the late-secondary and Graafian follicles of 4-week and 8-week ovaries (Fig. 3c and d). In addition to the expression of Af- 6 in granulosa cells, Af- 6 was strongly expressed in theca cells and some stromal cells of the ovarian interstitium (asterisks in Fig. 3b-d), but not in oocytes at any stages, which showed similarities to its expression in Leydig cells and some stromal cells of the testicular interstitium as described above (asterisks in Fig. 1a-d). Such strong Af-6 expression in interstitial steroidogenic cells in both testes and ovaries suggests its possible involvement in gonadal steroidogenesis, but the exact role of Af- 6 in these cells is unclear. By using confocal laser scanning microscopy, we also investigated the intracellular localization of Af- 6 and Usp9x in granulosa cells of the adult ovary (Fig. 4a and b). Positive reactions of both Af-6 and Usp9x were observed diffusely throughout their cytoplasm in granulosa cells of the primordial and primary follicles. We could not detect any Af- 6 reaction at specialized cell-cell junctions, such as adherens junctions, in granulosa cells. 

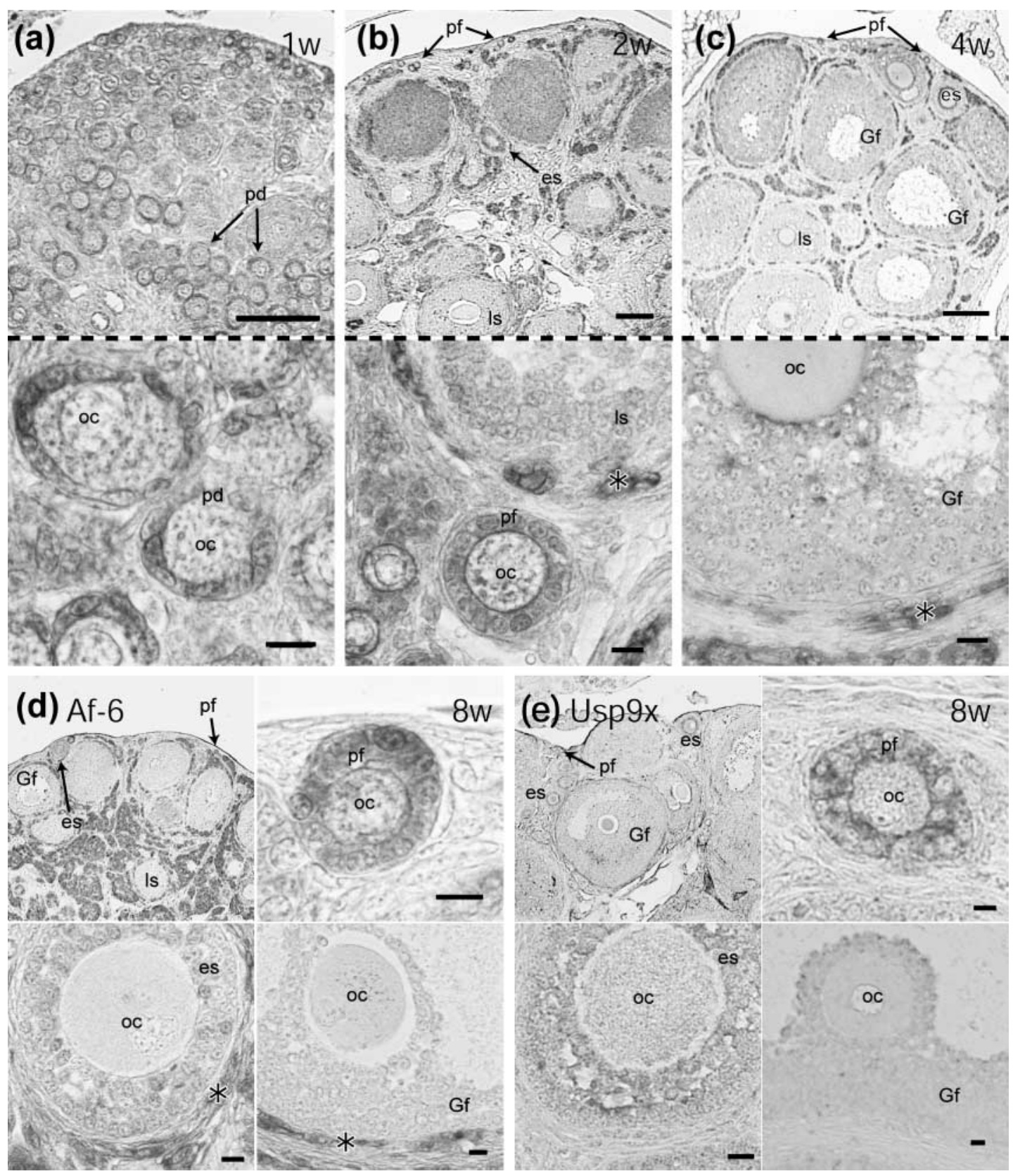

Figure 3 A close correlation of expression patterns between Af-6 (a-d) and Usp9x (e) in granulosa cells of mouse ovary. (a-d) Af-6 expression is predominantly found in follicular epithelial cells of primordial follicles in 1-week ovary (arrows in (a)). In granulosa cells of ovaries at 2 weeks (b), 4 weeks (c) and adult ( 8 weeks (d)), such reactions are continuously observed in all primordial (pd) and primary (pf) follicles and weakly in some secondary follicles (es), but they completely disappear in late-secondary (Is) and Graafian follicles (Gf). In addition, Af-6 is also expressed in theca cells and some stromal cells of the ovarian interstitium (asterisks in b-d). (e) In adult (8 week) ovary, Usp9x is highly expressed in primordial and primary follicles, but its expression is rapidly reduced after the late-secondary follicle. In $\mathrm{d}$ and e, a lower-magnified view of the ovary (upper left) and three more highly magnified images of primary follicles (upper right), early secondary follicles (lower left) and Graafian follicles (lower right) are shown. oc, oocyte. Scale bars in the upper plates of (a, b and c) represent $100 \mu \mathrm{m}$, while the other scale bars show $10 \mu \mathrm{m}$.

\section{PMSG treatment synchronously up-regulates both Af-6 and Usp9x expression slightly in Sertoli cells and strongly in granulosa cells}

We next examined the effect of FSH on Af-6 and Usp9x expression in testes and ovaries by treating the mice with PMSG, an FSH-like hormone. As a result, in testes and ovaries treated with PMSG, Af-6 reactions increased slightly in Sertoli cells (Fig. 5a and b) and strongly in granulosa cells (Fig. 5e and f) as judged by its expression levels in Leydig cells and theca cells (asterisks in Fig. 5a, b, e and f) respectively. In Sertoli cells, PMSG treatment resulted in a weak enhancement of Af- 6 expression levels in the whole cytoplasm of cells at stages VII-X (lowermost 

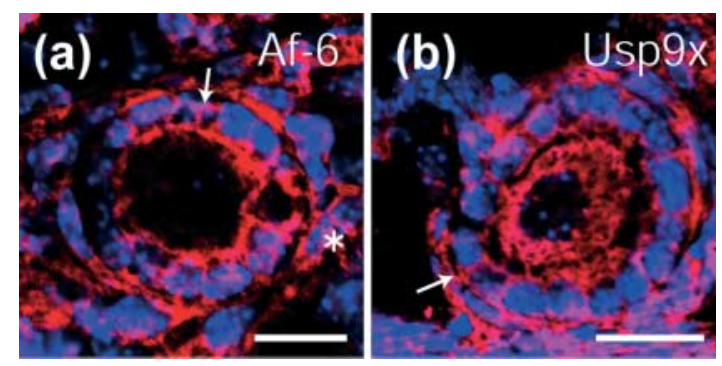

Figure 4 A diffuse expression of Af-6 (a) and Usp9x (b) in the whole cytoplasm of follicular epithelial cells of primary follicles in adult ovary. Positive reactions of both Af-6 and Usp9x are observed diffusely in the cytoplasm of granulosa cells (arrows). Both parts exhibit the combined image of Af- 6 or Usp9x expression (red) with nuclear staining (blue) in the same section. Red staining, Af-6 or Usp9x; blue staining, nuclei; asterisks, theca cells. Scale bars represent $10 \mu \mathrm{m}$.

plates in Fig. 5a and b) and in their basal compartment at stages XI-VI (middle plates in Fig. 5a and b), although no appreciable alterations in its intracellular distribution pattern was detected. This clearly suggested that PMSG treatment slightly enhances the Af- 6 expression level, but does not alter its intracellular distribution in Sertoli cells. Similar to Af-6 up-regulation in PMSG-treated testes, Usp9x expression also appeared to be slightly enhanced in the whole cytoplasm at stages VII-X (lowermost plates in Fig. $5 \mathrm{c}$ and d) and in their basal compartment at stages $\mathrm{XI}-\mathrm{VI}$ (middle plates in Fig. 5c and d). Only a weak Af-6 enhancement in Sertoli cells of the PMSG-treated testes may possibly be due to masking the effects of exogenously administrated PMSG by a constant high level of the endogenous circulatory FSH in normal adult male mice. In PMSG-treated ovaries, the expression levels of both Af-6 and Usp9x showed no appreciable change in granulosa cells of primordial and primary follicles (middle plates in Fig. 5e-h). However, the reactivity of both Af-6 and Usp9x was strongly up-regulated in granulosa cells of the late-secondary and Graafian follicles (lowermost panels in Fig. $5 \mathrm{f}$ and $\mathrm{h}$ ), in contrast to no detectable reaction in the control ovary at the same stages (lowermost panels in Fig. 5e and g). These observations indicated that PMSG treatment synchronously enhances the expression levels of Af-6 and Usp9x in both Sertoli and granulosa cells (Table 1). In addition, the number of late-secondary and Graafian follicles was found to have increased in PMSG-treated ovaries compared with that of the control ovary, but no appreciable histological changes were detected in the PMSG-treated testes.

Finally, we examined the expression levels of Af- 6 and Usp9x in control and PMSG-treated gonads by immunoblot analysis (Fig. 6). Immunoblot experiments using the testicular and ovarian extracts clearly demonstrated that anti-Af-6 and anti-Usp9x Ab specifically recognized a specific single band of approximately 205 and $220 \mathrm{kDa}$ respectively. These data clearly confirmed the high specificity of each $\mathrm{Ab}$ as was demonstrated in previous studies (Taya et al. 1998, Kanai-Azuma et al. 2000). PMSG treatment revealed an enhancement of Usp9x expression level, slightly in the testes and strongly in the ovaries (right-hand plates in Fig. 6a and b), which is consistent with the immunohistochemical data shown in Fig. 5c, d, g and h. Moreover, Af- 6 expression was moderately upregulated by PMSG treatment in the ovary (left-hand plates in Fig. 6b), but no appreciable difference between control and PMSG-treated testes was detected in the present immunoblot experiments (left-hand plates in Fig. 6a). Since Af- 6 is highly expressed in the testicular interstitial cells (asterisks in the top panels of Fig. $5 a$ and b), this result may be due to their masking a weak Af-6 up-regulation in Sertoli cells of the PMSG-treated testes.

\section{Discussion}

It has recently become clear that several junctional components are possible targets of the ubiquitin-proteosome degradation system. Occludin, a tight junction protein, was reported to be specifically ubiquitylated by the E3 ubiquitin-protein ligase Itch in vivo and in vitro, and its turnover is sensitive to inhibition of the proteasome pathway (Traweger et al. 2002). Hakai, another E3 ubiquitin ligase, has been shown to ubiquitylate and induce the endocytosis of the E-cadherin complex in epithelial cells (Fujita et al. 2002). Moreover, $\beta$-catenin, which accumulates at the cell-cell contact sites as a cadherin/catenin complex, is also regulated by the ubiquitin-proteasome pathway (Aberle et al. 1997, Salomon et al. 1997, Polakis 2000). As well as the post-translational regulation of tight and adherens junction proteins, a gap junction protein, Connexin43, is also degraded via the ubiquitin proteasome pathway (Laing \& Beyer 1995, Laing et al. 1997). Moreover, our previous report (Taya et al. 1998) showed a possible regulation of Af- 6 , an integral component of tight and adherens junctions, by an Usp9x-mediated ubiquitin pathway. These studies therefore clearly indicate that the balance between positive and negative regulators of ubiquitylation may likely be involved in the junction dynamics in various epithelial cells, including Sertoli and granulosa cells of mammalian gonads.

In the testis, the seminiferous epithelium contains two unique types of actin-mediated intercellular junction: Sertoli-Sertoli junctional complex (blood-testis barrier) and Sertoli-spermatid junctions (Russell \& Grisword 1993). During spermatogenesis, preleptotene spermatocytes migrate progressively from the basal to the adluminal compartments of the seminiferous epithelium traversing the Sertoli-Sertoli junction at stages VIII-IX (Cheng \& Mruk 2002, Lui et al. 2003). At the same stages, matured spermatozoa are released from the apical area of Sertoli cells into the lumen (i.e. spermiation). These two events are accompanied by extensive restructuring of both Sertoli-Sertoli and Sertoli-spermatid junctions. The present immunohistochemical study suggests that Usp9x, a deubiquitylating enzyme, and Af-6, a cell junction protein and a substrate of Usp9x, are co-localized at the sites of the actin-based junctions in a stage-dependent manner. 

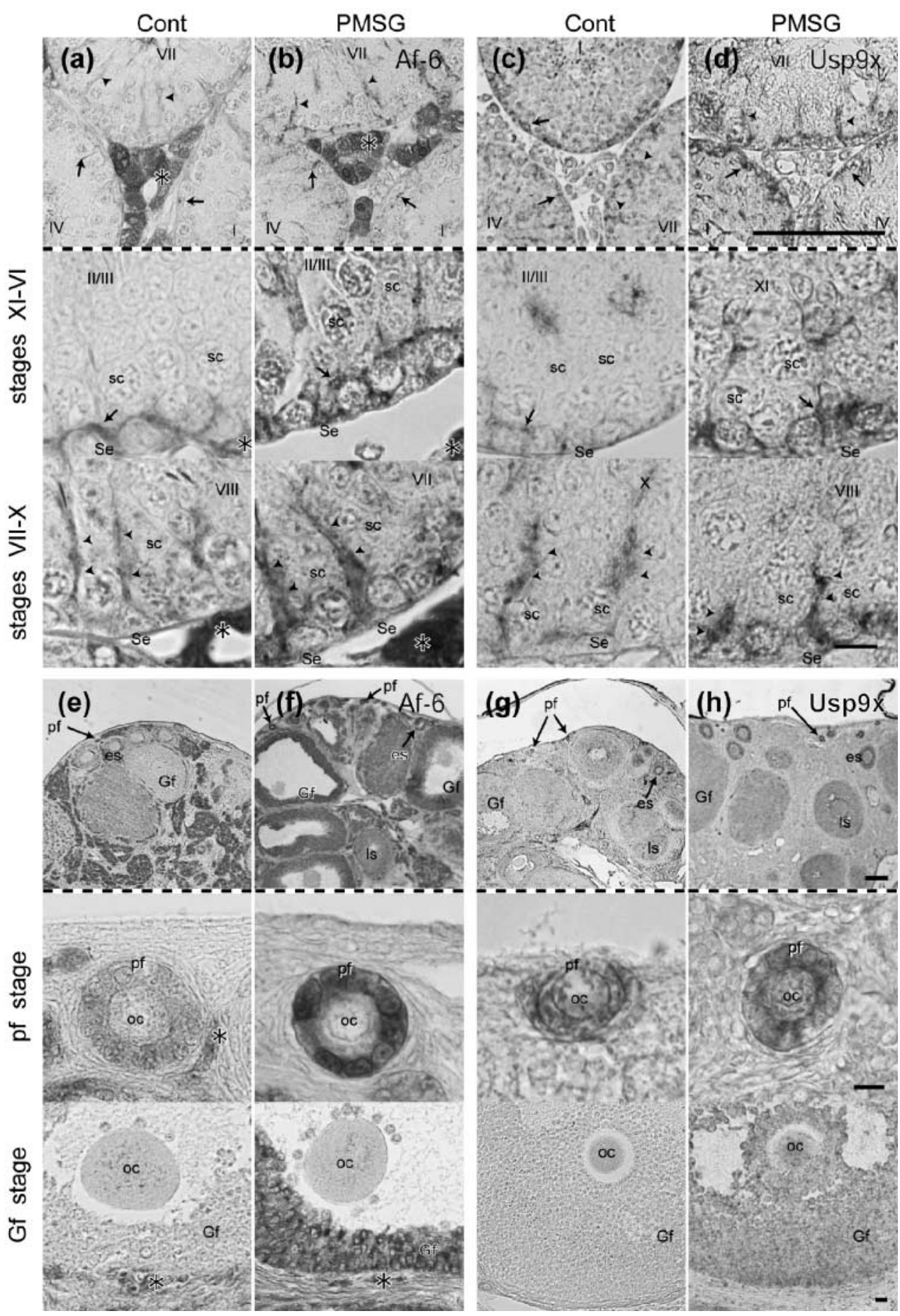

Figure 5 A stage-dependent enhancement of the expression levels of both Af-6 (a, b, e and f) and Usp9x (c, d, g and h) in Sertoli (a-d) and granulosa cells ( $\mathrm{e}-\mathrm{h}$ ) by PMSG treatment. PMSG-treated and control gonads (testes at 8 weeks, ovaries at 3 weeks) are exhibited in $\mathrm{b}, \mathrm{d}$, $\mathrm{f}$ and $\mathrm{h}$ and $\mathrm{a}$, c, e and g respectively. (a-d) Both Af-6 and Usp9x reactions show a weak enhancement in the whole cytoplasm at stages VII-X (arrowheads; lowermost plates) and in their basal compartment at stages XI-VI (arrows; middle plates) of PMSG-treated testes (b and d), as compared with those of the control testes ( $\mathrm{a}$ and $\mathrm{c}$ ). Each Roman numeral labeled on seminiferous epithelium shows the cycle stage. (e-h) In PMSG-treated ovaries (f and h), the expression levels of both Af-6 and Usp9x show no appreciable enhancement in granulosa cells of primordial and primary follicle (middle plates). However, their reactions are strongly up-regulated in granulosa cells of the late-secondary (Is) and Graafian follicles (Gf; lowermost panels), in contrast to no detectable reaction in granulosa cells at the same stages in the control (e and g). In each part, the two lower plates show more highly magnified images of the similar section in the uppermost plates. Se, Sertoli cell; sc, spermatocyte; pd, primordial follicle; pf, primary follicle; oc, oocyte. Asterisks represent Leydig cells ( $\mathrm{a}$ and b) or theca cells (e and f). Scale bars in the uppermost plates of $\mathrm{d}$ and $\mathrm{h}$ indicate $100 \mu \mathrm{m}$, while the other bars show $10 \mu \mathrm{m}$. 
Table 1 Synchronous enhancement of Af- 6 and Usp9x expression in Sertoli and granulosa cells by PMSG treatment. Changes in expression were determined by immunohistochemical analysis.

\begin{tabular}{|c|c|c|c|c|c|}
\hline & & \multicolumn{2}{|c|}{ Control } & \multicolumn{2}{|c|}{ PMSG } \\
\hline & & Af-6 & Usp9x & Af- 6 & Usp9x \\
\hline \multirow{4}{*}{$\begin{array}{l}\text { Sertoli cell } \\
\text { (stage) } \\
\text { Granulosa cell }\end{array}$} & $\mathrm{XI}-\mathrm{VI}$ & + & $+/-\sim+$ & $+\sim++$ & + \\
\hline & VII-X & + & $+/-\sim+$ & $+\sim++$ & + \\
\hline & $\begin{array}{l}\mathrm{pd} / \mathrm{pf} \\
\mathrm{l}_{\mathrm{s}}\end{array}$ & $\begin{array}{c}++ \\
-\end{array}$ & $\begin{array}{c}++ \\
-\end{array}$ & $\begin{array}{l}++ \\
++\end{array}$ & $\begin{array}{c}++ \\
+\end{array}$ \\
\hline & Gf & - & - & ++ & + \\
\hline
\end{tabular}

pd, primordial follicle; pf, primary follicle; Is, late-secondary follicle; Gf, Graafian follicle.

In brief, both Af-6 and Usp9x showed a diffuse distribution pattern in Sertoli cell cytoplasm at stages VII-X, while their reactions were more enriched in these two sites of Sertoli-Sertoli junctional complex and Sertolispermatid junction at stages $\mathrm{XI}-\mathrm{VI}$. This observation clearly suggests that Usp9x may possibly stabilize Af- 6 at these actin-mediated junctions more efficiently at stages $\mathrm{XI}-\mathrm{VI}$ than those at stages $\mathrm{VII}-\mathrm{X}$, which may result in the loosening of these junctions at stages VII-X. This is consistent with the fact that junctional degradation and reconstruction by spermiation and germ cell movement occurs at stages VIII-IX.

Af-6 (Afadin) is also shown to play an important role in nectin (an immunoglobulin-like adhesion molecule)-based intercellular adhesion by directly connecting nectin to the

(a) Testis

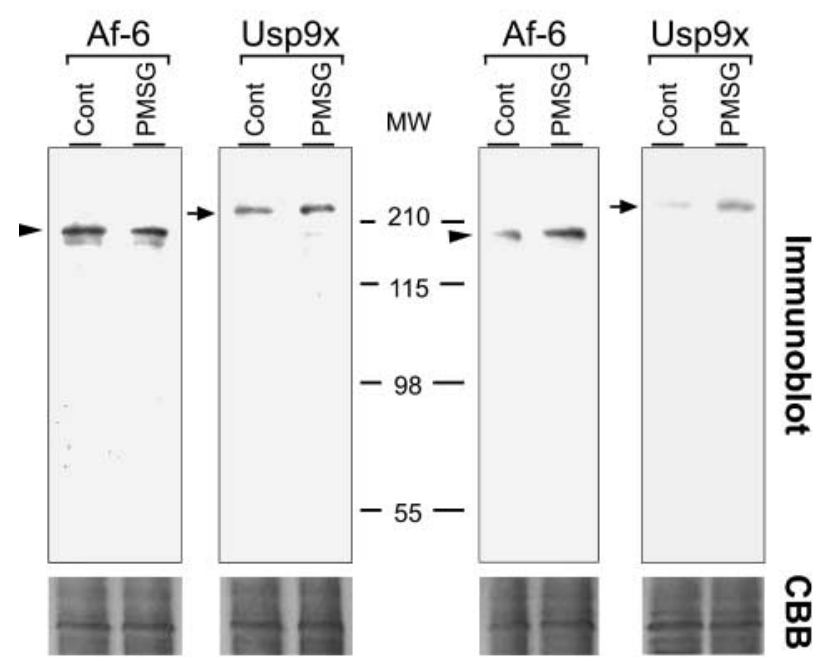

Figure 6 Immunoblot analysis showing the expression levels of Af- 6 and Usp9x in control and PMSG-treated testes (8 weeks (a)) and ovaries (3 weeks (b)). PMSG treatment up-regulates Usp9x expression level slightly in the testis and strongly in the ovary (right-hand plates in a and b). Moreover, Af- 6 expression is enhanced moderately in the ovary by PMSG treatment (left-hand plate in (b)), but no appreciable difference is detected between control and PMSG-treated testes (left-hand plate in (a)). Similar results were obtained in two other independent experiments. The CBB staining of the same samples is also shown in each lower plate. actin cytoskeleton (Takai \& Nakanishi 2003). In the seminiferous epithelium, Nectin-2, as well as Af-6, is also restricted to the Sertoli-Sertoli and Sertoli-spermatid junctions in Sertoli cells (Ozaki-Kuroda et al. 2002, Mueller et al. 2003). Nectin-2-deficient mice exhibit malespecific infertility and have defects in the later steps of sperm morphogenesis in the testis (Bouchard et al. 2000, Ozaki-Kuroda et al. 2002). Interestingly, in these mutant testes, the spermatids at steps 1-10 of spermiogenesis were normal, but at later steps (after step 11), the defects involving irregular shapes and prominent translucent vesicles were observed in all nuclei. The period when such spermatid defects appeared was clearly coincident with stages $\mathrm{XI}-\mathrm{VI}$ (i.e. spermatids at steps 11-15) when both Usp9x and Af-6 were restricted to the Sertoli-spermatid junction in this study. Therefore, such a close correlation between the abnormal spermatid differentiation in Nectin2-null testis and Usp9x localization at its junctional site suggests that Usp9x may contribute to the proper morphogenesis of spermatids by stabilizing the nectin-2-Af- 6 complex in the Sertoli-spermatid junction in mouse spermiogenesis.

In contrast to the restricted localization of Af- 6 and Usp9x at these two unique actin-based junctions in Sertoli cells, both Af-6 and Usp9x in the ovary showed a diffuse localization pattern in the whole cytoplasm of granulosa cells in this study. However, their expression in granulosa cells exhibited a stage-dependent pattern during follicular development: a high expression in primordial and primary follicles, but a rapid decline in the late-secondary to Graafian follicle. E-cadherin was previously shown to be involved in junctional dynamics of granulosa cells (Machell et al. 2000, Sundfeldt et al. 2000, Peluso et al. 2001). Interestingly, E-cadherin expression also shows a similar decline in granulosa cells of the late-secondary and Graafian follicles (Machell et al. 2000). These findings may therefore reflect the decrease in adherens junctions of maturing follicles, especially at the preovulatory stage (Rotmensch et al. 1986, Amsterdam \& Rotmensch 1987). Such a weak cell-cell adhesiveness among granulosa cells may likely be required for the rapid increase of the follicular volume and the subsequent ovulation during follicular maturation.

At present, there is a poor understanding of molecular mechanism of the adherens junction dynamics, and no evidence of the involvement of tight junction in granulosa cells of mammalian ovary. However, Schuster et al. (2004) have recently shown that, in the avian ovarian follicle, occludin, a tight junction protein, is expressed in granulosa cells of the immature follicle, and its expression levels clearly decrease with follicular maturation. They also demonstrated that FSH is capable of up-regulating occludin expression level in avian granulosa cells through a synergistic manner with activin $\mathrm{A}$ in vitro (Schuster et al. 2004). This is consistent with the present immunohistochemical data showing a strong enhancement of Af-6 expression in granulosa cells of late-secondary and 
Graafian follicles by PMSG treatment in vivo. It is well known that FSH plays a key role in the control and maintenance of normal gametogenesis through Sertoli cells (Nieschlag et al. 1999, Heckert \& Griswold 2002) or ovarian granulosa cells (Gromoll et al. 1996, O'Shaughnessy et al. 1996). Most interestingly, in this study, to accompany an increase of Af-6 expression, Usp9x was also found to be synchronously up-regulated in granulosa cells of the late-secondary and Graafian follicles in the ovaries treated with PMSG. These findings clearly emphasize a close association with Af-6 and Usp9x expression in granulosa cells, and further support the theory that Af-6 protein is regulated by Usp9x in these cells. This is also consistent with the present data showing a weak, but synchronous, enhancement of both Af-6 and Usp9x in Sertoli cells with PMSG treatment, although FSH function is not essential for Sertoli cell junction dynamics in the mouse testis (Kumar et al. 1997, Dierich et al. 1998, Abel et al. 2000). Only a weak Af-6 enhancement in Sertoli cells of the PMSG-treated testes may possibly be due to the masking of the effects of exogenously administered PMSG by a constant high level of the endogenous circulatory $\mathrm{FSH}$ in normal adult male mice. Additional experiments using FSH-depleted mouse models are required in future studies. Moreover, whether PMSG treatment promotes the Af-6 protein stability via Usp9x function or whether its signaling directly up-regulates Usp9x expression at the transcriptional level require further analysis.

Interestingly, as well as Af-6, $\beta$-catenin, an intracellular component of the cadherin-mediated cell adhesion complex, is shown to be a substrate of Usp9x (Taya et al. 1999). This clearly suggests the possibility that Usp9x regulates the stability of $\beta$-catenin, as well as Af-6, in Sertoli or granulosa cells during gametogenesis. In the testis, the cadherin/ $\beta$-catenin complex has been shown to be one of the functional units regulating the actin-based adherens junction dynamics in Sertoli cells (Lee \& Yan Cheng 2003). Moreover, $\beta$-catenin is reported to be localized in the Sertoli-Sertoli junctional complex and Sertoli-spermatid junction of Sertoli cells (Byers et al. 1994), which suggests the co-localization of $\beta$-catenin and Usp9x at these two sites in Sertoli cells. However, in the testis, $\beta$-catenin expression shows no noticeable stagedependent change throughout the cycle of seminiferous epithelium (Byers et al. 1994, Johnson \& Boekelheide 2002). This is in contrast to the stage-specific changes in the intracellular localization of both Usp9x and Af- 6 at these junctional sites in this study. In the ovary, E-cadherin was shown to be expressed in granulosa cells in a stagedependent manner (Machell et al. 2000), which shows a similar pattern to the present data of a strong expression of both Usp9x and Af-6 in primordial and primary follicles, but their rapid decline with follicular maturation. Moreover, $\beta$-catenin is highly expressed in granulosa cells (Sundfeldt et al. 2000). However, in the ovary, in contrast to the rapid decline of both Usp9x and Af-6 from the late-secondary follicle stage (Noma et al. 2002, this study), $\beta$-catenin was continuously expressed in granulosa cells of the late-secondary and Graafian follicles (Sundfeldt et al. 2000). These findings therefore suggest that the $\beta$-catenin expression level may not be regulated mainly by an Usp9x-mediated pathway in both Sertoli and granulosa cells. This is also consistent with a previous study (Pantaleon et al. 2001) showing a correct localization of $\beta$-catenin, but a rapid loss of Af- 6 , at cell-cell contacts in Usp9x-depleted embryos.

In conclusion, the present immunohistochemical study is the first to demonstrate a close correlation between Af- 6 and Usp9x expression patterns in both Sertoli and granulosa cells in a stage-specific manner during mouse gametogenesis. This clearly illustrates that Usp9x may deubiquitylate Af-6, promoting its protein stability in Sertoli and granulosa cells of mouse gonads, especially at the sites of the actin-based junctions of Sertoli cells in the testis. With regard to the recent report showing that neuronal overexpression of the Usp9x homologue (faf) enhances neuromuscular junction formation during Drosophila synaptic development (DiAntonio et al. 2001), the present findings therefore support the hypothesis that Af- 6 and Usp9x interaction may be one potential pathway to regulate the cell adhesion dynamics of both Sertoli and granulosa cells in mammalian gametogenesis.

\section{Acknowledgements}

The authors wish to thank Mr I Tsugiyama (The University of Tokyo) for his technical and secretarial assistance. This work was mainly supported by financial grants from the Ministry of Education, Science, Sports and Culture of Japan ( $\mathrm{Y}$ K and $\mathrm{MK}$ ).

\section{References}

Abel MH, Wootton AN, Wilkins V, Huhtaniemi I, Knight PG \& Charlton HM 2000 The effect of a null mutation in the follicle-stimulating hormone receptor gene on mouse reproduction. Endocrinology 141 1795-1803.

Aberle H, Bauer A, Stappert J, Kispert A \& Kemler R 1997 Beta-catenin is a target for the ubiquitin-proteasome pathway. EMBO Journal 16 3797-3804.

Amsterdam A \& Rotmensch S 1987 Structure-function relationships during granulosa cell differentiation. Endocrine Reviews 8 309-337.

Ben-Ze'ev A 1987 The role of changes in cell shape and contacts in the regulation of cytoskeleton expression during differentiation. Journal of Cell Science 8 (Suppl) 293-312.

Ben-Ze'ev A \& Amsterdam A 1987 In vitro regulation of granulosa cell differentiation: involvement of cytoskeletal protein expression. Journal of Biological Chemistry $2625366-5376$.

Bergh A, Damber JE, Lieu L \& Widmark A 1992 Does follicle-stimulating hormone or pregnant mare serum gonadotropin influence testicular blood flow in rats? International Journal of Andrology $\mathbf{1 5}$ $365-371$.

Boettner B, Govek EE, Cross J \& Van Aelst L 2000 The junctional multidomain protein AF- 6 is a binding partner of the Rap1A GTPase and associates with the actin cytoskeletal regulator profilin. PNAS 97 9064-9069.

Bouchard MJ, Dong Y, McDermott BM Jr, Lam DH, Brown KR, Shelanski M, Bellve AR \& Racaniello VR 2000 Defects in nuclear and cytoskeletal morphology and mitochondrial localization in 
spermatozoa of mice lacking nectin-2, a component of cell-cell adherens junctions. Molecular and Cellular Biology 20 2865-2873.

Brown GM, Furlong RA, Sargent CA, Erickson RP, Longepied G, Mitchell M, Jones MH, Hargreave TB, Cooke HJ \& Affara NA 1998 Characterization of the coding sequence and fine mapping of the human DFFRY gene and comparative expression analysis and mapping to the Sxr ${ }^{b}$ interval of the mouse $Y$ chromosome of the Dffry gene. Human Molecular Genetics 7 97-107.

Buchert M, Schneider S, Meskenaite V, Adams MT, Canaani E, Baechi T, Moelling K \& Hovens CM 1999 The junctional-associated protein AF- 6 interacts and clusters with specific Eph receptor tyrosine kinases at specialized sites of cell-cell contact in the brain. Journal of Cell Biology 144 361-371.

Byers SW, Sujarit S, Jegou B, Butz S, Hoschutzky H, Herrenknecht K, MacCalman C \& Blaschuk OW 1994 Cadherins and cadherinassociated molecules in the developing and maturing rat testis. Endocrinology 134 630-639.

Cadavid AL, Ginzel A \& Fischer JA 2000 The function of the Drosophila fat facets deubiquitinating enzyme in limiting photoreceptor cell number is intimately associated with endocytosis. Development 127 1727-1736.

Chen X \& Fischer JA 2002 A P element transformation vector for high levels of gene expression in germ-line cells of the ovary and undifferentiated cells in the developing eye of Drosophila. Plasmid $\mathbf{4 7}$ $61-65$.

Chen X, Overstreet E, Wood SA \& Fischer JA 2000 On the conservation of function of the Drosophila fat facets deubiquitinating enzyme and Fam, its mouse homolog. Development, Genes and Evolution 210 603-610.

Chen X, Zhang B \& Fischer JA 2002 A specific protein substrate for a deubiquitinating enzyme: liquid facets is the substrate of fat facets. Genes and Development 16 289-294.

Cheng CY \& Mruk DD 2002 Cell junction dynamics in the testis: Sertoli-germ cell interactions and male contraceptive development. Physiological Reviews 82 825-874.

DiAntonio A, Haghighi AP, Portman SL, Lee JD, Amaranto AM \& Goodman CS 2001 Ubiquitination-dependent mechanisms regulates synaptic growth and function. Nature 412 449-452.

Dierich A, Sairam MR, Monaco L, Fimia GM, Gansmuller A, LeMeur M \& Sassone-Corsi P 1998 Impairing follicle-stimulating hormone (FSH) signaling in vivo: targeted disruption of the FSH receptor leads to aberrant gametogenesis and hormonal imbalance. PNAS $9513612-13617$.

Ebnet K, Schulz CU, Meyer Zu Brickwedde MK, Pendl GG \& Vestweber D 2000 Junctional adhesion molecule interacts with the PDZ domain-containing protein AF-6 and ZO-1. Journal of Biological Chemistry 275 27979-27988.

Fair T 2003 Follicular oocyte growth and acquisition of developmental competence. Animal Reproduction Science 78 203-216.

Fischer-Vize JA, Rubin GM \& Lehmann R 1992 The faf facets gene is required for Drosophila eye and embryo development. Development 116 985-1000.

Fujita Y, Krause G, Scheffner M, Zechner D, Leddy HE, Behrens J, Sommer T \& Birchmeier W 2002 Hakai, a c-Cbl-like protein, ubiquitinates and induces endocytosis of the E-cadherin complex. Nature Cell Biology 4 222-231.

Gromoll J, Simoni M, Nordhoff V, Behre HM, De Geyter C \& Nieschlag E 1996 Functional and clinical consequences of mutations in the FSH receptor. Molecular and Cellular Endocrinology 125 177-182.

Hall NM, Brown GM, Furlong RA, Sargent CA, Mitchell M, Rocha D \& Affara NA 2003 Usp9y (ubiquitin-specific protease 9 gene on the $Y$ ) is associated with a functional promoter and encodes an intact open reading frame homologous to $U s p 9 x$ that is under selective constraint. Mammalian Genome 14 437-447.

Heckert LL \& Griswold MD 2002 The expression of the folliclestimulating hormone receptor in spermatogenesis. Recent Progress in Hormone Research 57 129-148.
Hershko A \& Ciechanover A 1998 The ubiquitin system. Annual Review of Biochemistry 67 425-479.

Hock B, Bohme B, Karn T, Yamamoto T, Kaibuchi K, Holtrich U, Holland S, Pawson T, Rubsamen-Waigmann $H$ \& Strebhardt $K$ 1998 PDZ-domain-mediated interaction of the Eph-related receptor tyrosine kinase EphB3 and the ras-binding protein AF6 depends on the kinase activity of the receptor. PNAS 95 9779-9784.

Huang Y, Baker RT \& Fischer-Vize JA 1995 Control of cell fate by a deubiquitinating enzyme encoded by the fat facets gene. Science 270 1828-1831.

Ikeda W, Nakanishi H, Miyoshi J, Mandai K, Ishizaki H, Tanaka M, Togawa A, Takahashi K, Nishioka H, Yoshida H, Mizoguchi A Nishikawa S \& Takai Y 1999 Afadin: a key molecule essential for structural organization of cell-cell junctions of polarized epithelia during embryogenesis. Journal of Cell Biology 146 1117-1132.

Janecki A, Jakubowiak A \& Steinberger A 1991 Effects of cyclic AMP and phorbol ester on transepithelial electrical resistance of Sertoli cell monolayers in two-compartment culture. Molecular and Cellular Endocrinology 82 61-69.

Johnson KJ \& Boekelheide K 2002 Dynamic testicular adhesion junctions are immunologically unique. I. Localization of p120 catenin in rat testis. Biology of Reproduction 66 983-991.

Jones MH, Furlong RA, Burkin H, Chalmers IJ, Brown GM, Khwaja O \& Affara NA 1996 The Drosophila developmental gene fat facets has a human homologue in Xp11.4 which escapes X-inactivation and has related sequences on Yq11.2. Human Molecular Genetics 5 1695-1701.

Kanai Y, Kanai-Azuma M, Noce T, Saido TC, Shiroishi T, Hayashi Y \& Yazaki K 1996 Identification of two Sox17 messenger RNA isoforms, with and without the high mobility group box region, and their differential expression in mouse spermatogenesis. Journal of Cell Biology 133 667-681.

Kanai-Azuma M, Mattick JS, Kaibuchi K \& Wood SA 2000 Co-localization of FAM and AF-6, the mammalian homologues of Drosophila faf and canoe, in mouse eye development. Mechanisms of Development 91 383-386.

Kumar TR, Wang Y, Lu N \& Matzuk MM 1997 Follicle stimulating hormone is required for ovarian follicle maturation but not male fertility. Nature Genetics 15 201-204.

Kuriyama M, Harada N, Kuroda S, Yamamoto T, Nakafuku $M$, Iwamatsu A, Yamamoto D, Prasad R, Croce C, Canaani E \& Kaibuchi K 1996 Identification of AF-6 and Canoe as putative targets for Ras. Journal of Biological Chemistry 271 607-610.

Laing JG \& Beyer EC 1995 The gap junction protein connexin43 is degraded via the ubiquitin proteasome pathway. Journal of Biological Chemistry 270 26399-26403.

Laing JG, Tadros PN, Westphale EM \& Beyer EC 1997 Degradation of connexin43 gap junctions involves both the proteasome and the lysosome. Experimental Cell Research 236 482-492.

Lee NP \& Yan Cheng C 2003 Regulation of Sertoli cell tight junction dynamics in the rat testis via the nitric oxide synthase/soluble guanylate cyclase $/ 3^{\prime}, 5^{\prime}$-cyclic guanosine monophosphate/protein kinase G signaling pathway: an in vitro study. Endocrinology 144 3114-3129.

Linnemann T, Geyer M, Jaitner BK, Block C, Kalbitzer HR, Wittinghofer A \& Herrmann C 1999 Thermodynamics and kinetic characterization of the interaction between the Ras binding domain of AF6 and members of the Ras subfamily. Journal of Biological Chemistry 274 13556-13562.

Lui WY, Mruk D, Lee WM \& Cheng CY 2003 Sertoli cell tight junction dynamics: their regulation during spermatogenesis. Biology of Reproduction 68 1087-1097.

Machell NH, Blaschuk OW \& Farookhi R 2000 Developmental expression and distribution of $\mathrm{N}$ - and $\mathrm{E}$-cadherin in the rat ovary. Biology of Reproduction 63 797-804.

Mandai K, Nakanishi H, Satoh A, Obaishi H, Wada M, Nishioka H, Itoh M, Mizoguchi A, Aoki T, Fujimoto T, Matsuda Y, Tsukita S \& Takai Y 1997 Afadin: a novel actin filament-binding protein with 
one PDZ domain localized at cadherin-based cell-to-cell adherens junction. Journal of Cell Biology 139 517-528.

Mitsunari M, Harada T, Tanikawa M, Iwabe T, Taniguchi F \& Terakawa N 1999 The potential role of stem cell factor and its receptor c-kit in the mouse blastocyst implantation. Molecular Human Reproduction 5 874-879.

Miyahara M, Nakanishi H, Takahashi K, Satoh-Horikawa K, Tachibana K \& Takai Y 2000 Interaction of nectin with afadin is necessary for its clustering at cell-cell contact sites but not for its cis dimerization or trans interaction. Journal of Biological Chemistry 275 613-618.

Mueller S, Rosenquist TA, Takai Y, Bronson RA \& Wimmer E 2003 Loss of nectin-2 at Sertoli-spermatid junctions leads to male infertility and correlates with severe spermatozoan head and midpiece malformation, impaired binding to the zona pellucida, and oocyte penetration. Biology of Reproduction 69 1330-1340.

Nieschlag E, Simoni M, Gromoll J \& Weinbauer GF 1999 Role of FSH in the regulation of spermatogenesis: clinical aspects. Clinical Endocrinology 51 139-146.

Noma T, Kanai $Y$, Kanai-Azuma M, Ishii M, Fujisawa M, Kurohmaru M, Kawakami H, Wood SA \& Hayashi Y 2002 Stage- and sexdependent expressions of Usp9x, an X-linked mouse ortholog of Drosophila Fat facets, during gonadal development and oogenesis in mice. Mechanisms of Development 119 (Suppl 1) S91-S95.

O'Shaughnessy PJ, Dudley K \& Rajapaksha WR 1996 Expression of follicle stimulating hormone-receptor mRNA during gonadal development. Molecular and Cellular Endocrinology 125 169-175.

Ozaki-Kuroda K, Nakanishi H, Ohta H, Tanaka H, Kurihara H, Mueller S, Irie K, Ikeda W, Sakai T, Wimmer E, Nishimune Y \& Takai Y 2002 Nectin couples cell-cell adhesion and the actin scaffold at heterotypic testicular junctions. Current Biology 12 1145-1150.

Pantaleon M, Kanai-Azuma M, Mattick JS, Kaibuchi K, Kaye PL \& Wood SA 2001 FAM deubiquitylating enzyme is essential for preimplantation mouse embryo development. Mechanisms of Development 109 151-160.

Peluso JJ, Pappalardo A \& Fernandez G 2001 E-cadherin-mediated cell contact prevents apoptosis of spontaneously immortalized granulosa cells by regulating Akt kinase activity. Biology of Reproduction $641183-1190$.

Polakis P 2000 Wnt signaling and cancer. Genes and Development 14 1837-1851.

Radziwill G, Erdmann RA, Margelisch U \& Moelling K 2003 The Bcr kinase downregulates Ras signaling by phosphorylating AF-6 and binding to its PDZ domain. Molecular and Cellular Biology 23 4663-4672.

Rotmensch S, Dor J, Furman A, Rudak E, Mashiach S \& Amsterdam A 1986 Ultrastructural characterization of human granulosa cells in stimulated cycle: correlation with oocyte fertilizability. Fertility and Sterility 45 671-679.

Vogl AW, Pfeiffer DC, Redenbach DM \& Grove BD 1993 Sertoli cell cytosckeleton. In The Sertoli Cell, pp 39-86. Eds LD Russell \& MD Griswold. Missouri: Cache River Press.

Salomon D, Sacco PA, Roy SG, Simcha I, Johnson KR, Wheelock MJ \& Ben-Ze'ev A 1997 Regulation of beta-catenin levels and localization by overexpression of plakoglobin and inhibition of the ubiquitin-proteasome system. Journal of Cell Biology 139 1325-1335.

Schuster MK, Schmierer B, Shkumatava A \& Kuchler K 2004 Activin a and follicle-stimulating hormone control tight junctions in avian granulosa cells by regulating occludin expression. Biology of Reproduction $701493-1499$.

Su L, Hattori M, Moriyama M, Murata N, Harazaki M, Kaibuchi K \& Minato N 2003 AF-6 controls integrin-mediated cell adhesion by regulating Rap1 activation through the specific recruitment of Rap1 GTP and SPA-1. Journal of Biological Chemistry 278 $15232-15328$.

Sun C, Skaletsky H, Birren B, Devon K, Tang Z, Silber S, Oates R \& Page DC 1999 An azoospermic man with a de novo point mutation in the Y-chromosomal gene USP9Y. Nature Genetics 23 $429-432$

Sundfeldt K, Piontkewitz Y, Billig H \& Hedin L 2000 E-cadherincatenin complex in the rat ovary: cell-specific expression during folliculogenesis and luteal formation. Journal of Reproduction and Fertility 118 375-385.

Takai Y \& Nakanishi H 2003 Nectin and afadin: novel organizers of intercellular junctions. Journal of Cell Science 116 17-27.

Taya S, Yamamoto T, Kano K, Kawano Y, Iwamatsu A, Tsuchiya T, Tanaka K, Kanai-Azuma M, Wood SA, Mattick JS \& Kaibuchi K 1998 The Ras target AF- 6 is a substrate of the fam deubiquitinating enzyme. Journal of Cell Biology 142 1053-1062.

Taya S, Yamamoto T, Kanai-Azuma M, Wood SA \& Kaibuchi K 1999 The deubiquitinating enzyme Fam interacts with and stabilizes beta-catenin. Genes to Cells 4 757-767.

Traweger A, Fang D, Liu YC, Stelzhammer W, Krizbai IA, Fresser F, Bauer HC \& Bauer H 2002 The tight junction-specific protein occludin is a functional target of the E3 ubiquitin-protein ligase itch. Journal of Biological Chemistry 277 10201-10208.

Wood SA, Pascoe WS, Ru K, Yamada T, Hirchenhain J, Kemler R \& Mattick JS 1997 Cloning and expression analysis of a novel mouse gene with sequence similarity to the Drosophila fat facets gene. Mechanisms of Development 63 29-38.

Yamamoto T, Harada N, Kano K, Taya S, Canaani E, Matsuura Y, Mizoguchi A, Ide C \& Kaibuchi K 1997 The Ras target AF-6 interacts with ZO-1 and serves as a peripheral component of tight junction in epithelial cells. Journal of Cell Biology 139 785-795.

Zhadanov AB, Provance DW Jr, Speer CA, Coffin JD, Goss D, Blixt JA, Reichert CM \& Mercer JA 1999 Absence of the tight junctional protein AF-6 disrupts epithelial cell-cell junctions and cell polarity during mouse development. Current Biology 26 880-888.

Zuccotti M, Ponce RH, Boiani M, Guizzardi S, Govoni P, Scandroglio R, Garagna S \& Redi CA 2002 The analysis of chromatin organisation allows selection of mouse antral oocytes competent for development to blastocyst. Zygote $1073-78$.

Received 23 October 2004

First decision 13 January 2004

Revised manuscript received 13 August 2004

Accepted 16 August 2004 